\title{
Tennis: a promising approach to family-centered physical activity and health promotion
}

\author{
Nicholas Dombrowski \& Jennifer Hanson \\ Department of Food, Nutrition, Dietetics and Health, Kansas State University, USA.
}

\begin{abstract}
Despite global goals to reverse the prevalence of obesity and inactivity, little to no progress has been made. This article presents the details of a tennis-based, familycentered program that can serve as a model for future wellness interventions. The program succeeded in providing a source of physical activity for the children and adults involved. Participant feedback confirmed that the program was well received and that an expanded program would be feasible. Tennis appears to be a viable platform for health promotion, and tennis professionals looking to build partnerships for the purpose of growing the game should keep in mind potential public health stakeholders.
\end{abstract}

\author{
Key words: racket sports, \\ nutrition, wellness, family, physical \\ activity.
}

Received: 30 Jan 2021

Accepted: 05 Mar 2021

Corresponding author: Jennifer Hanson. Email: jhanson2@ksu.edu

\section{INTRODUCTION}

Childhood obesity has become a public health epidemic. The average body mass index (BMI) of both boys and girls has increased and is continuing to trend upward (NCD Risk Factor Collaboration, 2017). Individuals who are obese in childhood are more likely to be obese as adults. They are also more likely to suffer from chronic diseases such as hypertension and type 2 diabetes, as well as from social problems (Lanigan $\&$ Singhal, 2009). Despite having nationwide goals to reverse the prevalence of obesity, little to no progress has been made (Skinner et al., 2018). Current research suggests that multi-component physical activity programs for youth are successful in reducing weight and that parental involvement can enhance these effects (Bluford et al., 2007). Additionally, sound dietary habits can lead to a reduced risk of chronic disease, lower risk of obesity, and improved educational performance (Boeing et al., 2012; Burns et al.,2018; Faught et al., 2017; Shi et al., 2013). Unfortunately, many children are confused as to what 'healthy eating' is, and not all children receive education in school regarding the topic (Edwards \& Hartwell, 2012). The literature suggests a relationship between the dietary habits of children and those of their parents, and positive dietary changes in parents could lead to positive dietary habits in children (Cullen et al., 2000). As such, the purpose of this pilot study was to develop and assess the feasibility of a family-centered tennis program that incorporated health and nutrition education for both the children and adults participating. This approach has the advantage of involving parents, being multicomponent, and providing both parents and children the skills necessary to enjoy a multi-generational lifetime sport.

\section{METHODS}

\section{Participants}

Twenty-three families with a total of 31 children and 20 adults enrolled in the program. The children were between

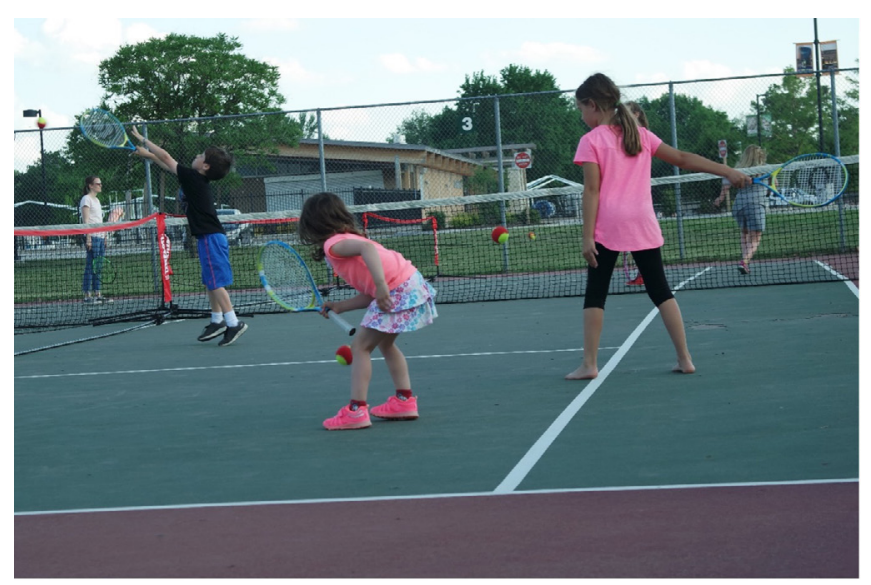

five and ten years of age, and prior tennis experience was not a requirement for enrollment. Participants provided written consent/assent and completed a health screening prior to engaging in on-court activities. The study protocol was approved by the Institutional Review Board at Kansas State University.

\section{Program}

The curriculum for the tennis program was adapted directly from the United States Tennis Association (USTA) Red Ball Team Challenge curriculum. This curriculum falls under the umbrella of Net Generation, the youth brand created by the USTA to "spread the love of tennis to a new generation by empowering those that will teach them" (Morris \& Davies, 2018). Through Net Generation, coaches are trained and provided with curricula designed to target specific skill ranges. The Red Ball Team Challenge is a set of activities that introduce the participant to the sport of tennis. These lessons are ideal for beginning players of all ages and aim to increase physical activity time while reducing wait time in lines. To better adapt to beginning players, the program utilizes red 
balls that are larger and easier to hit than traditional tennis balls. Smaller, mobile nets are used to section off traditional full-sized tennis courts thereby creating a playing area better sized for beginners. All coaches in the current familybased program were provided on-court training by a USTA representative on how to best implement the curriculum.

Complementing the tennis activities were a set of nutrition and health lessons adapted from information provided by the United States Department of Agriculture (USDA) and the Office of Disease Prevention and Health Promotion (ODPHP). Lessons revolving around eating more vegetables, being an active family, and being a healthy role model were used. Lessons about building healthy eating habits and consuming less sugars were adapted from ODPHP materials.

\section{Program structure}

The program consisted of five one-hour lessons offered over the span of five weeks. The lessons were offered at two locations within Kansas during the spring of 2018. Parents were given the option to participate on-court with their child/ children or to remain off the court. All participants were loaned a tennis racquet and ball to be used during the lessons and at home to practice in between lessons. Each lesson began with a group warm-up and stretching activities. During this warm-up period, one of the nutrition education topics selected for the program was introduced as the topic of the day. Following the warm-up, participants were led through five or six activities from the Net Generation, Red Ball Challenge curriculum. During this time, children under eight years of age were grouped together and children eight years old and older were grouped together to minimize the skill difference between groups. During the first lesson, activities focused on getting participants accustomed to holding a tennis racquet and performing hand-eye coordination activities with the ball. During the next lesson, previous activities were reviewed, and newer, more advanced activities were introduced. By the final lesson, activities were centered around multiple tennis shots and volley play.

In between activities were allotted water breaks. During each water break, coaches further provided education on the nutrition topic of the day. After all activities had been completed, all participants were gathered for a discussion about the topic. Parents were given informational handouts from the USDA and ODPHP, and children were given interactive handouts that they could color and keep. All participants were reminded of activities performed that day that could be practiced at home between practices.

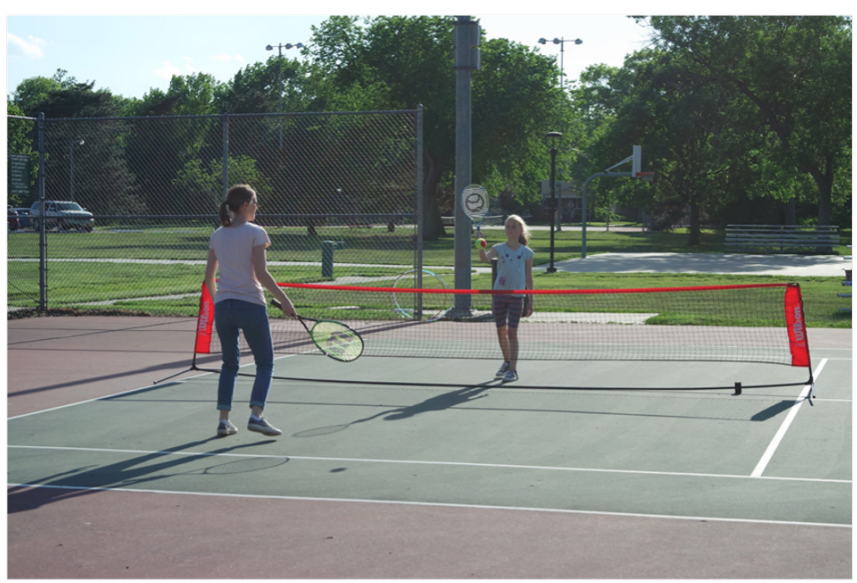

Table 1

Family-centered tennis program health topics.

\begin{tabular}{l} 
Week 1 \\
\hline Children: MyPlate-Fueling for activity \\
Adults: The Dietary Guidelines \& MyPlate- Eating for health \\
and performance
\end{tabular}

\begin{tabular}{l}
\hline Week 2 \\
\hline Children: Eating more fruits and vegetables \\
Adults: Promoting increased fruit and vegetable \\
consumption
\end{tabular}

\begin{tabular}{l} 
Week 3 \\
\hline Children: Pick a healthy drink
\end{tabular}

Children: Pick a healthy drink

Adults: Limiting sugar sweetened beverages

\begin{tabular}{l}
\hline Week 4 \\
\hline Children: Being physically active \\
Adults: Being physically active \& limiting screen time \\
\hline Week 5 \\
\hline Children: Building a healthy snack \\
Adults: Promoting adequate sleep \\
\hline
\end{tabular}

\section{Program evaluation}

Following the final lesson, families were invited to fill out an online survey regarding their participation and experience within the program.

\section{RESULTS}

Sixty-five percent $(n=15)$ of the families enrolled in the program completed the survey. Of the families who completed the survey, twelve (80\%) attended at least four of the five sessions, eleven (73\%) had at least one adult participate on the court with their child/children, and eleven (73\%) families reported practicing tennis weekly outside of the program. When asked about continuing to play tennis in the future, eleven (73\%) families reported interest in attending another program of similar intensity, fourteen (93\%) families reported that they would be interested in attending a program that targeted a higher skill set, and nine (60\%) families reported that they had already signed up or planned to sign up for tennis lessons outside of the program.

Feedback responses such as, "It was a nice activity for children and parents to do together," and "It was fun because it provided my daughter and I with a fun activity to do together," exemplify the value families placed on the program as a result of it being an activity that they could participate in together.

\section{DISCUSSION}

Results confirm the program was well accepted and that an expanded program would be feasible and has the potential to support sustainable behavior change. The program succeeded 
in providing a source of physical activity for the children and adults involved. It also equipped parents with the knowledge and skills needed to incorporate sound nutrition and physical activity into everyday family life. In addition, most children enjoyed learning about tennis and expressed interest in continuing to play the sport after the completion of the lessons.

Today's youth engage in an array of behaviors that threaten their overall health and wellbeing (Kann et al., 2018). Yet, sports-based programs may be an effective approach to promoting wholesome values and improving wellness. Tennis professionals looking to build partnerships for the purpose of growing the game should keep in mind potential public health stakeholders. From a health promotion perspective, tennis appears to have numerous benefits, including improved aerobic fitness, improved bone health, and a reduced risk of cardiovascular morbidity and mortality (Pluim et al., 2007). Tennis is a lifetime sport and while modifications may be necessary, it is a great option for increasing physical activity among all age groups. Because many locations offer public courts that can be accessed for free or for a minimal fee, tennis-based wellness programs can be developed with relatively low facility costs.

Although additional future research is needed to examine the effectiveness of the education provided to determine its role in future programs, based on the findings of this pilot program, tennis appears to be a great platform for health promotion.

Research Grant Sources: The program described in this study was partially funded by the United States Tennis Association- Missouri Valley, Serving Up Tennis Grant.

\section{REFERENCES}

Bluford, D. A., Sherry, B., \& Scanlon, K. S. (2007). Interventions to prevent or treat obesity in preschool children: a review of evaluated programs. Obesity, 15(6), 1356-1372. https://doi.org/10.1038/oby.2007.163

Boeing, H., Bechthold, A., Bub, A., Ellinger, S., Haller, D., Kroke, A., LeschikBonnet, E., Müller, M. J., Oberritter, H., Schulze, M., Stehle, P., \& Watzl, B. (2012). Critical review: vegetables and fruit in the prevention of chronic diseases. European Journal of Nutrition, 51(6), 637-663. https://doi.org/10.1007/s00394-012-0380-y
Burns, R. D., Fu, Y., Brusseau, T. A., Clements-Nolle, K., \& Yang, W. (2018). Relationships among physical activity, sleep duration, diet, and academic achievement in a sample of adolescents. Preventive Medicine Reports, 12 , 71-74. https://doi.org/10.1016/j.pmedr.2018.08.014

Cullen, K. W., Baranowski, T., Rittenberry, L., \& Olvera, N. (2000). Social-environmental influences on children's diets: results from focus groups with African-, Euro- and Mexican-American children and their parents. Health Education Research, 15(5), 581-590. https://doi.org/10.1093/her/15.5.581

Edwards, J. S., \& Hartwell, H. H. (2002). Fruit and vegetables-attitudes and knowledge of primary school children. Journal of Human Nutrition and Dietetics, 15(5), 365-374. https://doi.org/10.1046/j.1365-277x.2002.00386.x

Faught, E. L., Ekwaru, J. P., Gleddie, D., Storey, K. E., Asbridge, M., \& Veugelers, P. J. (2017). The combined impact of diet, physical activity, sleep and screen time on academic achievement: a prospective study of elementary school students in Nova Scotia, Canada. The International Journal of Behavioral Nutrition and Physical Activity, 14(1), 29. https://doi.org/10.1186/s12966-017-0476-0

Kann, L., McManus, T., Harris, W. A., Shanklin, S. L., Flint, K. H., Queen, B., Lowry, R., Chyen, D. Whittle, L., Thornton, J., Lim, C. Bradford, D., Yamakawa, Y., Leon, M., Brener, N., \& Ethier, K. A. (2018). Youth Risk Behavior Surveillance - United States, 2017. Morbidity and Mortality Weekly Report. Surveillance Summaries, 67(8), 1-114. https://doi.org/10.15585/mmwr.ss6708a1

Lanigan, J., \& Singhal, A. (2009). Early nutrition and long-term health: a practical approach. The Proceedings of the Nutrition Society, 68(4), 422-429. https://doi.org/10.1017/S002966510999019X

Morris, C., \& Davies, K. (2018). Net Generation: A generation of innovation. ITF Coaching and Sport Science Review, 76 (26): 17-19.

NCD Risk Factor Collaboration (2017). Worldwide trends in body-mass index, underweight, overweight, and obesity from 1975 to 2016: a pooled analysis of 2416 population-based measurement studies in 128.9 million children, adolescents, and adults. Lancet, 390(10113), 2627-2642. https://doi.org/10.1016/S0140-6736(17)32129-3

Pluim, B. M., Staal, J. B., Marks, B. L., Miller, S., \& Miley, D. (2007). Health benefits of tennis. British Journal of Sports Medicine, 41(11), 760-768. https://doi.org/10.1136/bjsm.2006.034967

Shi, X., Tubb, L., Fingers, S. T., Chen, S. \& Caffrey, J. L. (2013). Associations of physical activity and dietary behaviors with children's health and academic problems. The Journal of School Health, 83(1), 1-7. https://doi.org/10.1111/j.1746-1561.2012.00740.x

Skinner, A. C., Ravanbakht, S. N., Skelton, J. A., Perrin, E. M., \& Armstrong, S. C. (2018). Prevalence of obesity and severe obesity in US children, 1999-2016. Pediatrics, 141(3), e20173459. https://doi.org/10.1542/peds.2017-3459

You are free to Share - copy and redistribute the material in any medium or format - and Adapt the content - remix, transform, and build upon the material for any purpose, even commercially under the following terms:

Attribution: You must give appropriate credit, provide a link to the license, and indicate if changes were made. You may do so in any reasonable manner, but not in any way that suggests the licensor endorses you or your use. 